\title{
Effects of short- and long-term regular exercise on reproductive tissue in streptozotocin-induced diabetic male Wistar rats
}

\author{
Zahra Mogaddami ${ }^{1}$, Farzam Sheikhzadeh ${ }^{1}$, Homeira Hatami ${ }^{1}$, Seyed Mahdi Banan Khojasteh ${ }^{1}$, \\ Nazli Khajehnasiri ${ }^{2,3}$, Ali Reza Ali Hemmati ${ }^{4}$, Ali Dastranj ${ }^{5}$
}

${ }^{1}$ Department of Animal Sciences, Faculty of Biological Sciences, University of Tabriz, Tabriz, Iran; ${ }^{2}$ Department of Animal Sciences, Faculty of Biological Sciences, Shahid Beheshti University, Tehran, Iran; ${ }^{3}$ Department of Biological Sciences, Faculty of Basic Sciences, Higher Education Institute of Rab-Rashid, Tabriz, Iran; ${ }^{4}$ Department of Anatomical Sciences, Faculty of Medicine, Tabriz University of Medical Sciences, Tabriz, Iran; ${ }^{5}$ Women's Reproductive Health Research Center, Tabriz University of Medical Sciences, Tabriz, Iran

E-mail:dr_dastranj@yahoo.com

Objective. Reproductive disorders are one of the complications of diabetes mellitus. Since conflicting results have been obtained from different studies, which examined serum levels of cytokines in patients with diabetes, and considering the fact that the origin of cytokines cannot be accurately determined from their serum changes, attempts were made in the present study to study histological changes and testicular tissue levels of TNF- $\alpha$ and IL-1 in rats treated with exercise. Considering the effects of exercise in reducing blood sugar level and its complications, two types of short-term and long-term regular exercises were also considered to evaluate their effects on male reproductive tissues.

Methods. In this study, 60 male rats with the weight range of $250 \pm 50 \mathrm{~g}$ were used and were randomly divided into six groups (10 rats each). Healthy groups included sedentary control group, and groups treated with two and eight weeks of exercise. Rats with type 1 diabetes (induced by streptozotocin) included sedentary control group, groups treated with two and eight weeks of exercise (six groups). All groups were evaluated in terms of testicular tissue levels of TNF- $\alpha$ and IL-1 using ELISA and the histometry of spermatogonia, primary spermatocytes, Sertoli cells, epithelial thickness, diameter of veins, and thickness of the seminiferous tubule.

Results. Histological changes resulting from diabetes, particularly in the diameter of testicular veins and a number of cells, including Sertoli, highlights the important fact that tissue perfusion in patients with diabetes is especially crucial, in a way that exercise proved useful for tissue structures by offsetting this complication. Measurement of the cytokines IL- 1 and TNF- $\alpha$ in the current study showed that perfusion problems are more important in diabetic complications than inflammatory factors.

Conclusions. The main result of this research is recommendation of investigating the tissue of interest for diagnosis of diabetes complications, measuring inflammatory mediators of tissue rather than evaluating their serum concentrations, and focusing on vascular complications as a major complication of diabetes. Furthermore, regular exercise could help improve the function of reproductive organs in healthy groups and prevent diabetes infertility complications to an acceptable degree in diabetic groups.

Key words: regular exercise, type 1 diabetes, histometry, TNF- $\alpha$, IL-1, spermatogonial and Sertoli cells, epithelial thickness, seminiferous tubule 
Hyperglycemia is known as a hemosedentary disorder, the continuance of which causes many complications in various organs in the long run (Kawahito et al. 2009). Hyperglycemia is one of the characteristics of diabetes, associated with various side effects including sexual disorders, impotence, and infertility (Cudicini et al. 1997; Amaral et al. 2006; Roy et al. 2013; Sisman et al. 2014).

Advanced glycation end products (AGEs) in diabetes cause disorders such as cardiovascular problems, hypoxia, and inflammation, by increasing the expression of proinflammatory cytokines and chemokines, including tumor necrosis factor- $\alpha$ (TNF- $\alpha$ ) and interleukin-1 (IL-1) (Sisman et al. 2014). Physiologically, TNF- $\alpha$ and IL-1 play important roles in regulation and homeostasis of the reproductive organs, such as facilitating the proliferation of Sertoli cells and increasing testosterone secretion. Moreover, their protein receptors have been observed in Leydig and Sertoli cells (Cudicini et al. 1997; Rozwadowska et al. 2001). TNF- $\alpha$ and IL-1 are cytotoxic at high concentrations, and may cause tissue damage (Esposito et al. 2002; Foss et al. 2007). There are conflicting results or changing the values of these cytokines in the blood of diabetic patients. Duration of the disease is one of the effective factors in changing the values of these two cytokines (Aizzat et al. 2010; Long et al. 2012; Belotto et al. 2010).

In addition to changes in serum levels of these two proteins in diabetic patients, testicular tissue changes are seen in these people. For example, due to increased blood glucose levels and glycosylation of membrane proteins in diabetic animals, thickening of basal membrane in seminiferous tubules is associated with impaired fluidity of membrane proteins which, in turn, causes irregularities in the interstitial space between seminiferous tubules. Irregularities in the epithelium membrane during the disease are manifested as reduced thickness of the epithelium of the tubule under light microscopes (Kurdak et al. 2010).

Considering positive effects of exercise in controlling blood glucose levels, it has been reported that blood glucose level in exercised diabetic animals is significantly lower than those of sedentary diabetic animals. Regular exercise brings blood sugar closer to normal levels (Petersen and Pedersen 2005; Hesari et al. 2014).

According to the abovementioned information, hyperglycemia probably causes sexual and reproductive disorders in people with diabetes by changing the levels of serum cytokines as well as changing the testicular tissue. With regard to the effective role of regular moderate exercise in reducing blood glucose levels, we decided to investigate the impact of multiple periods of regular moderate exercise on cytokines levels and histological changes of testicular tissue in the diabetic animal model in the present study.

\section{Materials and Methods}

Animals. In this study, 60 adult male Wistar rats with the weight rage of $250 \pm 50 \mathrm{~g}$ were prepared from Laboratory of Animal Breeding Department of Tabriz University. During the experiment, the temperature at the breeding environment was $22 \pm 2{ }^{\circ} \mathrm{C}$. Moreover, rats were kept at a 12:12 h light-dark cycle (7:00 a.m. to 7:00 p.m.) while having free access to food and water.

Design of the experiment. Animals were randomly divided into six groups (ten each): 1) sedentary control group (SC); 2) two-week healthy exercised group (2HE); 3) eight-week healthy exercised group (8HE); 4) sedentary diabetic group (SD); 5) two-week diabetic exercised group (2DE); and 6) eight-week diabetic exercised group (8DE).

Induction of diabetes. Diabetes was induced by intraperitoneal injection of $60 \mathrm{mg} / \mathrm{kg}$ streptozotocin dissolved in sterile normal saline until blood sugar level increased to $14 \mathrm{mmol} / \mathrm{l}$. Fasting blood glucose was measured using Elegance glucometer with a small cut at the end of the tails $48 \mathrm{~h}$ after induction. Blood glucose levels of above $250 \mathrm{mg} / \mathrm{dl}$ were considered as an indicator of diabetes. In addition, frequent urination and polydipsia were evident in rats that received streptozotocin. Therefore, the rats in these groups were kept in groups of 3 per cage. It should be noted that healthy groups also received proportional amounts of sterile normal saline (Petersen and Pedersen 2005).

Exercise protocol. Exercise group rats were exercised for $1 \mathrm{~h}$ per day, 5 days per week, at a speed of $22 \mathrm{~m} / \mathrm{min}$ on the treadmill (Febbraio et al. 2003). As a warm-up, the speed of the machine was increased from $5 \mathrm{~m} / \mathrm{min}$ to $22 \mathrm{~m} / \mathrm{min}$ within the initial $10 \mathrm{~min}$ utes. Moreover, the speed was gradually reduced to 5 $\mathrm{m}$ min in last 10 minutes, to return them to the initial state. Rats in control groups were placed on the treadmill as long while the machine was off (Petersen and Pedersen 2005).

Sample collection. All rats were anesthetized 24 $\mathrm{h}$ after the last day of exercise by intraperitoneal injection (i.p.) of ketamine $100 \mathrm{mg} / \mathrm{kg}$ and xylazine $5 \mathrm{mg} / \mathrm{kg}$ (Petersen and Pedersen 2005). After opening the abdominal cavity, testicles were removed from the scrotum. Right testicles of the animals were immediately frozen in liquid nitrogen and were transferred 
to the freezer $\left(-80^{\circ} \mathrm{C}\right)$ for the measurement of TNF- $\alpha$ and IL-1 proteins. Left testicles were placed in $10 \%$ formalin for pathological and histometrical studies.

ELISA. Tissues were removed from the freezer $\left(-80^{\circ} \mathrm{C}\right)$ and $600 \mu \mathrm{l}$ of cold phosphate-buffer saline (ice cold $1 \%$ ) which was stored overnight in the freezer at $-18^{\circ} \mathrm{C}$ was added to each specimen. Then half of the testis $(70 \mathrm{mg})$ was prepared using a manual homogenizer. Next, they were centrifuged using a refrigerated centrifuge $\left(4^{\circ} \mathrm{C}\right)$ at $5000 \times \mathrm{g}$ for $5 \mathrm{~min}$, and eventually, their supernatant was immediately removed and IL-1 and TNF- $\alpha$ were measured based on ELISA kit guidelines.

Pathological and histometrical study of seminiferous tubules and testicular vessels. After various histological preparation stages, all specimens were stained using hematoxylin-eosin method. Also, a total of 3 slides were prepared from each specimen and 10 fields of view were selected for each slide (10 rats $x$ 3 slides $\times 10$ fields of view $=300$ microscope fields for each group).

To assess histological changes, area (diameter), and thickness of seminiferous tubule walls as well as possible irregularities of cells in these structures were studied. To measure the area of seminiferous tubules, diameter and thickness of the tubules wall were calculated. Moreover, ocular micrometer with $40 \times$ magnification was used to measure the diameter of tubules. The number of spermatogonia, primary spermatocytes and Sertoli cells was also considered in this study.

Data Analysis. Data were analyzed by one-way ANOVA using SPSS-16. In this study, $\mathrm{p}<0.05$ was considered as the significance level, and values were expressed as mean \pm standard error.

\section{Results}

Effect of exercise on TNF- $\alpha$ and IL-1. According to the results, there was no significant difference in TNF- $\alpha$ and IL- 6 protein levels within none of the experimental groups ( $p>0.05)$ (Figure 1).

Effect of exercise on testicular histometry. In eight-week healthy exercised group, the number of spermatogonial cells was increased compared to control $(\mathrm{p}<0.05)$. Also, the number of these cells in eight-week healthy exercised group was significantly higher than in two-week healthy exercised group. Furthermore, the number of primary spermatocytes showed a significant increase in eightweek healthy exercise group compared to another third group (sedentary control, sedentary diabetic and two-week diabetic exercised). Also, the exercise caused a significant increase in number of primary spermatocytes in eight-week diabetic exercise group compared to the sedentary diabetic group $(\mathrm{p}<0.05)$ (Figure 2B). Diabetes caused a significant reduction in the number of Sertoli cells in sedentary diabetic groups compared to control group. However, exercise increased the number of these cells in eightweek healthy exercise group $(\mathrm{p}<0.05)$ (Figure 2C).

Diabetes reduced the vessel epithelial thickness, but this change was not significant. However, in both eight-week diabetic and healthy exercised groups, this characteristic of vessels was significantly improved $(\mathrm{p}<0.05)$ (Table 1, Figure 3$)$. Moreover, in the sedentary diabetic group, vessel diameter showed a significant reduction compared to control, and exercise increased vessel diameter in diabetic exercised groups. Between all experimental groups, there was no significant difference in the seminif-

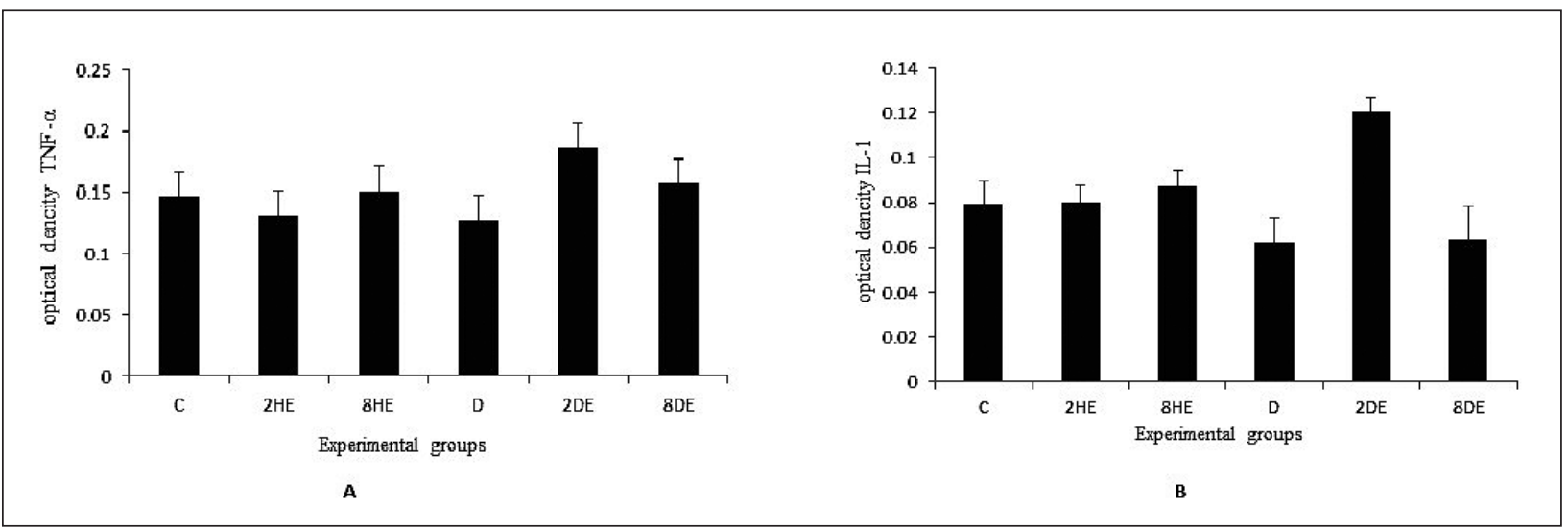

Figure 1. Optical density of tumor necrosis factor- $\alpha$ (TNF- $\alpha$ ) (A) and interleukin-6 (IL-6) (B). The data present mean \pm SEM. Abbreviations: $\mathrm{C}$ - sedentary control group; $2 \mathrm{HE}$ - two-week healthy exercised group; $8 \mathrm{HE}$ - eight-week healthy exercised group; $\mathrm{D}$ - sedentary diabetic group; 2DE - two-week diabetic exercised group; 8DE - eight-week diabetic exercised group. 


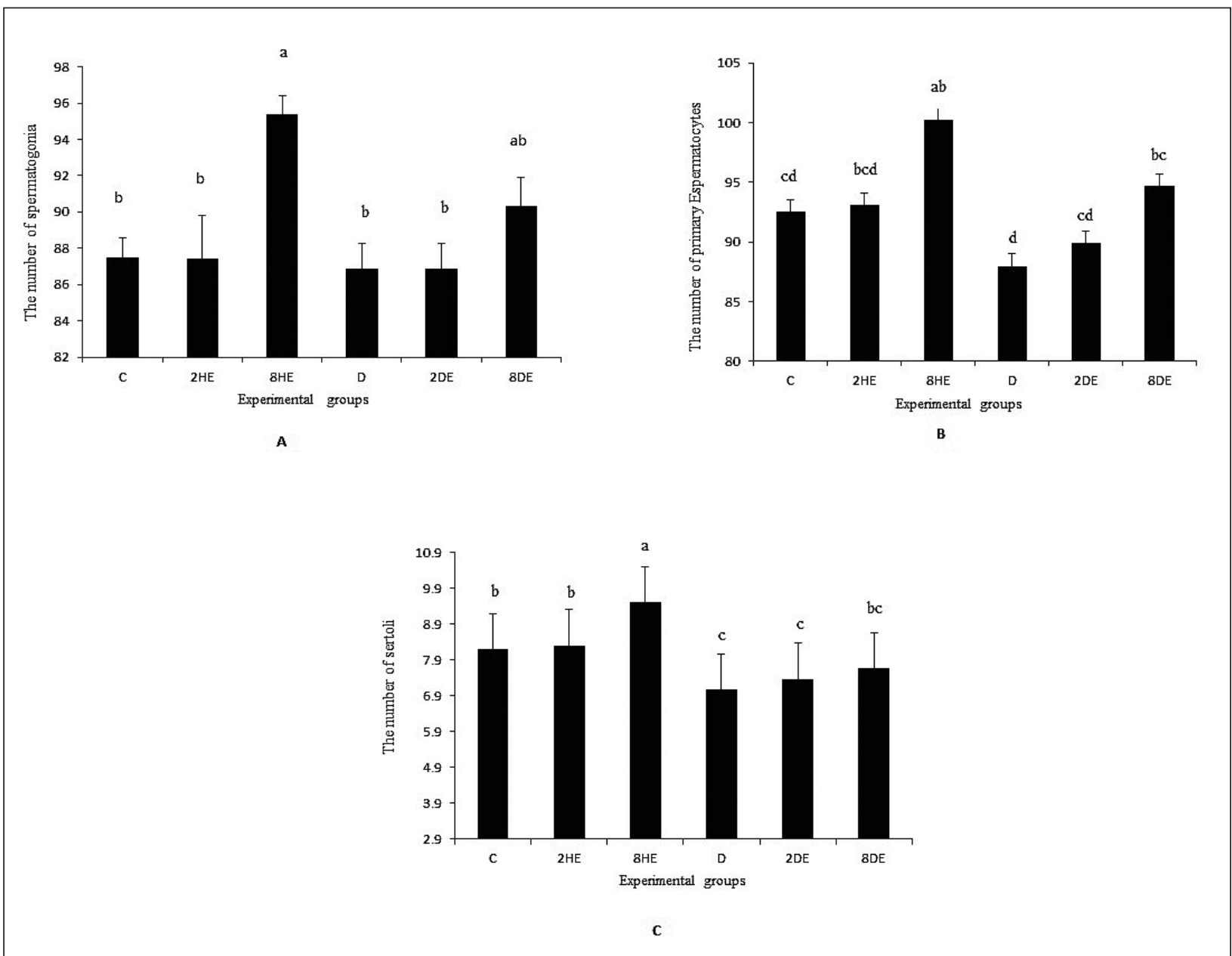

Figure 2. The number of spermatogonia (A), primary spermatocytes (B) and Sertoli cells (C). The data present mean \pm SEM, different superscripts indicate significant differences $(\mathrm{p}<0.05)$. Abbreviations: $\mathrm{C}-$ sedentary control group; $2 \mathrm{HE}-$ two-week healthy exercised group; 8HE - eight-week healthy exercised group; D - sedentary diabetic group; 2DE - two-week diabetic exercised group; $8 \mathrm{DE}$ - eight-week diabetic exercised group.

Table 1

Thickness and diameter of vessel and seminiferous tubule.

\begin{tabular}{|c|c|c|c|c|c|c|}
\hline $\begin{array}{ll}\text { Parameter } & \text { Group } \\
\end{array}$ & $\mathrm{C}$ & $2 \mathrm{HE}$ & $8 \mathrm{HE}$ & $\mathrm{D}$ & $2 \mathrm{DE}$ & $8 \mathrm{DE}$ \\
\hline $\begin{array}{l}\text { Vessel Epithelium Thickness } \\
(\mu \mathrm{m})\end{array}$ & $0.47 \pm 0.04^{\mathrm{ab}}$ & $0.46 \pm 0.03^{\mathrm{ab}}$ & $0.52 \pm 0.03^{\mathrm{a}}$ & $0.36 \pm 0.04^{\mathrm{b}}$ & $0.35 \pm 0.03^{b}$ & $0.55 \pm 0.05^{\mathrm{a}}$ \\
\hline $\begin{array}{l}\text { Vessel Diameter } \\
(\mu \mathrm{m})\end{array}$ & $4.90 \pm 0.6^{\mathrm{a}}$ & $3.35 \pm 0.64^{\mathrm{ab}}$ & $3.31 \pm 0.39^{\mathrm{ab}}$ & $2.47 \pm 0.31^{\mathrm{b}}$ & $3.17 \pm 0.49^{\mathrm{ab}}$ & $4.2 \pm 0.65^{\mathrm{ab}}$ \\
\hline $\begin{array}{l}\text { Seminiferous Epithelium } \\
\text { Thickness }(\mu \mathrm{m})\end{array}$ & $2.40 \pm 0.06$ & $2.30 \pm 0.09$ & $2.52 \pm 0.04$ & $2.19 \pm 0.08$ & $2.23 \pm 0.07$ & $2.28 \pm 0.15$ \\
\hline $\begin{array}{l}\text { Seminiferous Diameter } \\
(\mu \mathrm{m})\end{array}$ & $76.61 \pm 1.39$ & $74.39 \pm 2.39$ & $78.54 \pm 1.96$ & $75.84 \pm 2.73$ & $83.30 \pm 2.92$ & $75.15 \pm 3.06$ \\
\hline
\end{tabular}

The data present mean \pm SEM, $\mathrm{p}<0.05$, different superscripts indicate significant differences. Abbreviations: $\mathrm{C}$ - sedentary control group; $2 \mathrm{HE}$ - two-week healthy exercised group; $8 \mathrm{HE}$ - eight-week healthy exercised group; D - sedentary diabetic group; $2 \mathrm{DE}$ two-week diabetic exercised group; 8DE - eight-week diabetic exercised group. 
erous epithelium thickness and diameter $(\mathrm{p}<0.05)$ (Table 1, Figure 4).

\section{Discussion}

Based on results of this study, injection of streptozotocin and induction of type I diabetes in male $\mathrm{Wi}$ star rats showed no significant changes in testicular levels of TNF- $\alpha$ and IL-1 within two months of affliction (Figure 1).

To evaluate serum levels of cytokines in patients with diabetes, several studies have been conducted with conflicting results. One reason for such results is the duration of infection; it should be noted that cytokines serum changes can not accurately determine their origin. Accordingly, testicular tissue was used in the study.

TNF- $\alpha$ is generated as first pro-inflammatory cytokine from immune system cells in the chronic inflammatory pathway, and plays a role in calling other cytokines to the inflammation site (Lysiak 2004). IL-1 is also one of the main mediators of innate immunity and inflammation (Carneiro et al. 2010). These proteins are not only involved in the inflammatory process, but also important in the apoptotic pathway (Gomez et al. 1997). These two cytokines are synthesized in mammalian testicles in the spermatocyte cells and macrophages of connective tissue in the seminiferous tubules. Receptors of these cytokines exist in rat and human testicles, and mRNA of receptors can be seen in Sertoli and Leydig cells and testicular macrophages of all species (De et al. 1993; Carneiro et al. 2010). Physiologically, these two proteins play an important role in testicular tissue homeostasis, while their high levels are pathological (Hesari and Khajehnasiri 2013), such that serum concentrations of TNF- $\alpha$ and IL-1 may increase up to 2 to 3 times higher than their normal levels in chronic diseases such as diabetes (Lysiak 2004). Thus, in the present study the observed testicular tissue changes in diabetic group are not probably mediated by TNF- $\alpha$ and IL-1 inflammatory factors within 2 months of diabetes.

In chronic diseases such as diabetes, the role of oxidative stress and glycation end products in tissue damages should not be neglected. It has been shown that regular exercise can reduce diabetes complications by reducing blood sugar level (Febbraio et al. 2003); of course, with the assumption that following such reduction, levels of inflammatory mediators will also be reduced in the intended tissues. Different kinds of exercise were considered in this study to evaluate their effect on levels of cytokines TNF- $\alpha$ and

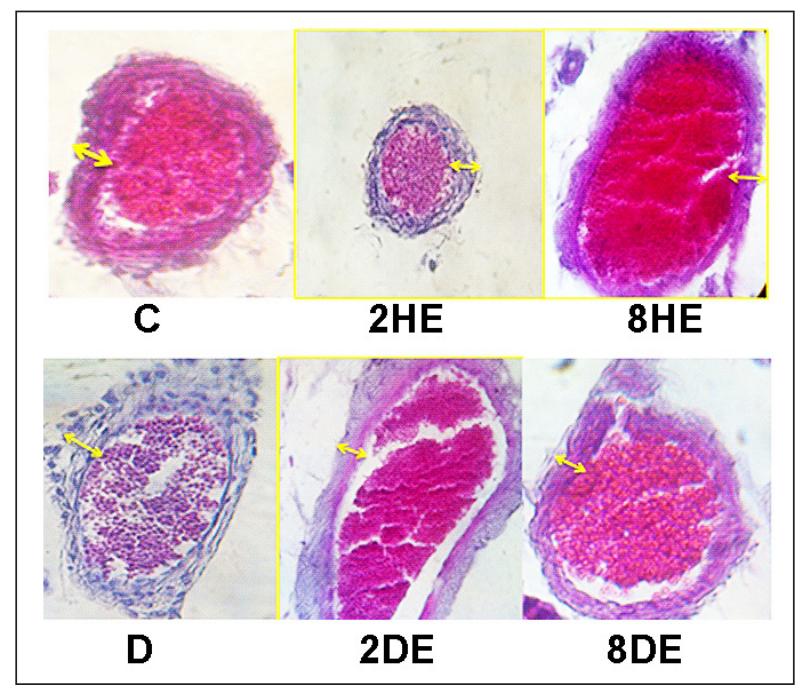

Figure 3. The testes vessel epithelium changes in streptozotocin-induced diabetic male adult Wistar rats after short- and long-term regular exercise. Abbreviations: $\mathrm{C}$ - sedentary control group; $2 \mathrm{HE} \mathrm{-} \mathrm{two-week} \mathrm{healthy} \mathrm{exercised} \mathrm{group;} 8 \mathrm{HE} \mathrm{-}$ eight-week healthy exercised group; D - sedentary diabetic group; $2 \mathrm{DE}$ - two-week diabetic exercised group; 8DE - eightweek diabetic exercised group.

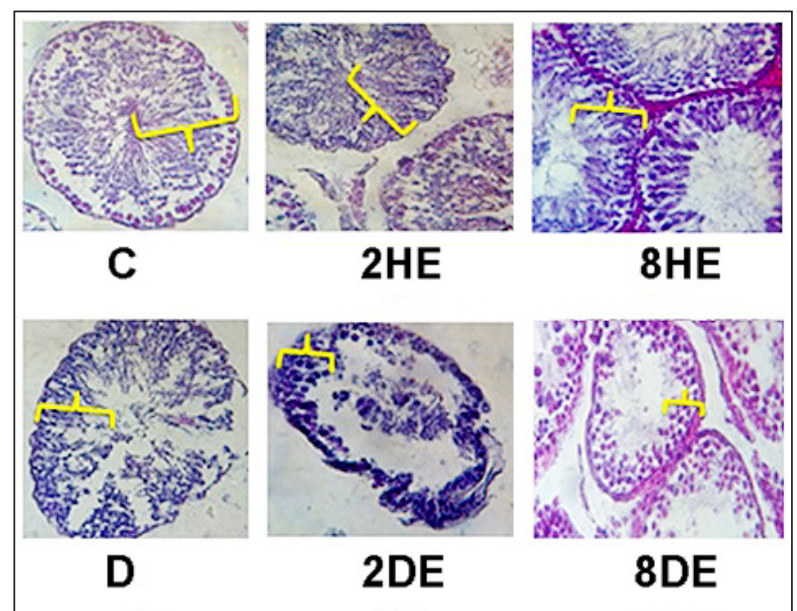

Figure 4. The seminiferous epithelium changes in streptozotocin-induced diabetic male adult Wistar rats after shortand long-term regular exercise. Abbreviations: $\mathrm{C}$ - sedentary control group; $2 \mathrm{HE} \mathrm{-} \mathrm{two-week} \mathrm{healthy} \mathrm{exercised} \mathrm{group;} 8 \mathrm{HE}$ - eight-week healthy exercised group; D - sedentary diabetic group; $2 \mathrm{DE}$ - two-week diabetic exercised group; 8DE - eightweek diabetic exercised group.

IL-1. Long-term (8 weeks) and short-term (2 weeks) exercises did not change the values of these factors in any group; of course exercise itself did not cause any destructive inflammatory effect in this time period. 
In a number of observations, lack of change in serum levels of IL-1 and TNF- $\alpha$ has been reported in healthy and diabetic individuals treated with exercise (Bonyadi et al. 2009). It should be noted that there are very few studies on the effects of exercise on testicular tissue levels of IL-1 and TNF- $\alpha$. Also, with regular exercise after 4, 8, and 12 weeks following diabetes induction, no significant changes were reported in serum concentrations of IL- 1 and TNF- $\alpha$ in the diabetic group compared with the sedentary control group (Stewart et al. 2007; Touvra et al. 2011; Safarzade et al. 2012). Of course, there are conflicting results of serum level measurements, such as the effect of onemonth resistance training on inflammatory factors, which lead reduced serum levels of IL- 6 and TNF- $\alpha$ in the diabetic group compared with the control group (Talebi-Garakani and Safarzade 2013). In addition, a significant decrease was reported in serum levels of IL-18 (a family member of IL-1) after 12 weeks of aerobic activity. According to findings of a number of previous studies on humans, 12 weeks of moderate walking can reduce serum inflammatory markers such as IL-1, IL-6, IL-10, and IFN- $\gamma$ (Oberbach et al. 2006; Yu et al. 2009). The difference between the results of previous studies with those of the current research can be attributed to the key difference of this research, i.e. histological measurements of inflammatory factors as well as duration and type of exercise.

Testicular levels of IL-1 and TNF- $a$ did not change, and microscopic symptoms of inflammation, such as the accumulation of inflammatory cells, were not observed either; therefore, there may be factors other than the inflammatory pathway involved in tissue changes.

Wall thickness and vessel diameter are used as indicators for measuring physiologic function of testicular veins (Goldhammer et al. 2005; Talebi-Garakani and Safarzade 2013). In this research, attempts were made to study tissue changes, especially effects of type 1 diabetes on testicular veins, so as to reveal causes of tissue damages in the case of any change.

Since thickness and diameter of epithelium of vessel walls were reduced in diabetic group compared with the control group, it could be considered a factor causing tissue problems in diabetes. As long-term regular exercise managed to offset this complication, it can be concluded that exercise has positive effects in this regard. Also, a decrease was observed in the vessel diameter of healthy exercise groups compared with the control group, which may be caused sympathetic nerve stimulation following exercise (Madrid et al. 2013).

Continuation of regular exercise showed a significant reductive impact on diameter and thickness of vessel walls in diabetic groups, which is considered as one of the outstanding achievements of the current research. Therefore, considering reduced blood sugar in diabetic rats (Febbraio et al. 2003), it can be concluded that long-term regular exercise plays an important role in reducing diabetes complications in the testicular tissue, such as reducing the amount of vascular endothelial growth factor (VEGF) and nitric oxide molecule (NO) in patients with diabetes following the reduction in vessel diameter and blood supply (Lee and Cheng 2008; Noble et al. 2013). Induction of diabetes caused a significant decrease in Sertoli cells in diabetic rats compared with the control group, which was to some extent offset by both short- and long-term exercises. Interestingly, exercise increased the number of these cells in healthy groups as well (Figure 3, Foss et al. 2007).

One of important reasons for reduced number of Sertoli cells and testicular damage in diabetic rats is the decrease in pituitary-gonadal axis hormones ( $\mathrm{LH}$ and FSH) (Dohle et al. 2003). Reduced levels of LH and FSH hormones have been reported in diabetic rats, along with impaired spermatogenesis and Sertoli cell destruction (Wachtel et al. 1991). Moreover, lactate production from glucose is proposed as an important source of energy in Sertoli cells, which is reduced with a reduction in insulin levels in diabetic conditions. As a result, another reason for reduced number of Sertoli cells in the diabetic group compared with the control group can be destruction of or changes in the cell mitochondria organelle due to hyperglycemia and apoptosis (Amaral et al. 2006; Abeer 2010).

Long-term regular exercise can probably have a positive effect on the number of important reproductive cells such as Sertoli cells, by affecting cell proliferation process or inhibition of cell damages. In this study, long-term exercise has offset the adverse effect of diabetes in the diabetic group with a slight increase in the number of Sertoli cells. Therefore, the positive effects of euglycemia caused by long-term exercise were likely to be more evident by continuing the exercise process.

According to the investigation conducted on the number of primary spermatocytes in the treatment groups of the study, it can be seen that diabetes has reduced the number of these cells compared with the control group, although this reduction is not significant, and both types of exercise could significantly affect the number of these cells (Figure 2B).

The potential impact of long-term exercise in the healthy group compared with the control group is indicative of protective effects of exercise against age- 
associated oxidative damages in proteins, lipids, and DNA contained in cells involved in spermatogenesis including primary spermatocytes. (Shiraishi and Naito 2005) Studies show that regular exercises play an important role in suppressing these symptoms; there was no significant difference in terms of testicular tissue damage in older age rats treated with exercise compared with sedentary younger rats (Chigurupati et al. 2008). Thus, it is likely that the number of spermatocytes cells is increased in this study as a result of protective effects of exercise against damages caused by oxidative stress. However, it should not be forgotten that an increase in tissue perfusion and metabolism of the whole body are benefits of regular exercise, which are also plentiful in reproductive structures.

The number of spermatogonial cells was significantly increased in response to long-term regular exercise. Such an effect, along with the improvement of vascular status of testicular tissues, especially in healthy rats is indicative of an increase in fertility potential in healthy people through long-term regular exercise. In addition, exercise increased to some extent the number of these cells in diabetic group (Figure 2A).

Although there was no significant difference in this study between control and sedentary diabetic groups in the number of spermatogonial cells, conflicting results can be referred to, including histological findings in which a significant difference was observed in the number of spermatogonial cells between groups 6 and 20 weeks after diabetes induction (NavarroCasado et al. 2010). Duration of affliction can be the cause of such impacts.

Although no significant changes in thickness and diameter of seminiferous tubules under the influence of diabetes were found, and short- and long-term exercises did not show any significant changes in groups (Table 1), it is likely that such severe complications have occurred due to the duration of diabetes, which requires further investigations.

It is also possible the direct effect of physical activity on primary spermatocytes (at preleptotene stage) has been one of the most important reasons of change in the diameter and thickness of seminiferous tubules by reducing diabetic oxidative stress conditions and preventing decrease in testosterone secretion.

Results of the current research could be the start of the new perspective that vascular changes (small and large) are more important than other diabetic complications. To assess inflammation in a tissue, inflammatory mediators in that tissue should be measured, because in many studies these mediators, including different cytokines, are measured in serum. According to the findings, serum inflammatory mediators may enter blood circulation from different tissues. Testicular levels of TNF- $\alpha$ and IL1 did not change in sedentary diabetic group compared with the control group, and no inflammation symptoms were observed in this tissue, while vascular changes were evident and more sensitive cells were affected by diabetes (hyperglycemia) and vascular changes.

The main result of this research is recommendation of investigating the tissue of interest for diagnosis of diabetes complications, measuring inflammatory mediators of tissue rather than evaluating their serum concentrations, and focusing on vascular complications as a major complication of diabetes. Furthermore, regular exercise could help improve the function of reproductive organs in healthy groups and prevent diabetes infertility complications to an acceptable degree in diabetic groups.

\section{References}

Abeer AS. Role of aminoguanidine on the testis of streptozotocin-induced diabetic albino rat, a light and electron microscopic study. Egypt J Histol 33, 451-466, 2010.

Aizzat O, Yap SW, Sopiah H, Madiha MM, Hazreen M, Shailah A, Junizam WW, Syaidah AN, Srijit D, Musalmah M, Anum MY. Modulation of oxidative stress by Chlorella vulgaris in streptozotocin (STZ) induced diabetic Sprague-Dawley rats. Adv Med Sci 55, 281-288, 2010.

Amaral S, Moreno AJ, Santos MS, Seica R, Ramalho-Santos J. Effects of hyperglycemia on sperm and testicular cells of Goto-Kakizaki and streptozotocin-treated rat models for diabetes. Theriogenology 66, 2056-2067, 2006.

Belotto MF, Magdalon J, Rodrigues HG, Vinolo MA, Curi R, Pithon-Curi TC, Hatanaka E. Moderate exercise improves leucocyte function and decreases inflammation in diabetes. Clin Exp Immunol 162, 237-24, 2010.

Bonyadi M, Badalzadeh R, Mohammadi M, Poozesh S, Salehi I. The effect of regular training on plasma cytokines response in healthy and diabetic rats. Saudi Med J 30, 1390-1394, 2009.

Carneiro FS, Webb RC, Tostes RC. Emerging role for TNF- $\alpha$ in erectile dysfunction. J Sex Med 7, 3823-3834, 2010.

Chigurupati S, Son TG, Hyun DH, Lathia JD, Mughal MR, Savell J, Li SC, Nagaraju GP, Chan SL, Arumugam TV, Mattson MP. Lifelong running reduces oxidative stress and degenerative changes in the testes of mice. J Endocrinol 199, 333-341, 2008. 
Cudicini C, Lejeune H, Gomez E, Bosmans E, Ballet F, Saez J, Jegou B. Human Leydig cells and Sertoli cells are producers of interleukins-1 and-6. J Clin Endocrinol Metab 82, 1426-1433, 1997.

De SK, Chen HL, Pace JL, Hunt JS, Terranova PF, Enders GC. Expression of tumor necrosis factor-alpha in mouse spermatogenic cells. Endocrinology 133, 389-396, 1993.

Dohle GR, Smit M, Weber RF. Androgens and male fertility. World J Urol 21, 341-345, 2003.

Esposito K, Nappo F, Marfella R, Giugliano G, Giugliano F, Ciotola M, Quagliaro L, Ceriello A, Giugliano D. Inflammatory cytokine concentrations are acutely increased by hyperglycemia in human's role of oxidative stress. Circulation 106, 2067-2072, 2002.

Febbraio MA, Steensberg A, Starkie RL, McConell GK, Kingwell BA. Skeletal muscle interleukin-6 and tumor necrosis factor- $\alpha$ release in healthy subjects and patients with type 2 diabetes at rest and during exercise. Metabolism 52, 939-944, 2003.

Foss NT, Foss-Freitas MC, Ferreira MA, Cardili RN, Barbosa CM, Foss MC. Impaired cytokine production by peripheral blood mononuclear cells in type 1 diabetic patients. Diabetes Metab 33, 439-443, 2007.

Goldhammer E, Tanchilevitch A, Maor I, Beniamini Y, Rosenschein U, Sagiv M. Exercise training modulates cytokines activity in coronary heart disease patients. Int J Cardiol 100, 93-99, 2005.

Gomez E, Morel G, Cavalier A, Lienard MO, Haour F, Courtens JL, Jegou B. Type I and type II interleukin-1 receptor expression in rat, mouse, and human testes. Biol Reprod 56, 1513-1526, 1997.

Hesari FS, Khajehnasiri N. Phosphorylated connexin 43 protein levels attenuation in the retina of adult diabetic male rats, by regular moderate exercise. J Phys Pharm Adv 3, 199-206, 2013.

Hesari FS, Khajehnasiri N, Khojasteh SM, Soufi FG, Dastranj A. Attenuation of phosphorylated connexin-43 protein levels in diabetic rat heart by regular moderate exercise. Arch Iran Med 17, 569-573, 2014.

Kawahito S, Kitahata H, Oshita S. Problems associated with glucose toxicity: role of hyperglycemia-induced oxidative stress. World J Gastroenterol 15, 4137-4142, 2009.

Kurdak H, Sandikci S, Ergen N, Dogan A, Kurdak SS. The effects of regular aerobic exercise on renal functions in streptozotocin induced diabetic rats. J Sports Sci Med 9, 294-299, 2010.

Lee NP, Cheng CY. Nitric oxide and cyclic nucleotides: their roles in junction dynamics and spermatogenesis. Oxid Med Cell Longev 1, 25-32, 2008.

Long T, Liu G, Wang Y, Chen Y, Zhang Y, Qin D. TNF- $\alpha$, erectile dysfunction, and NADPH oxidase-mediated ROS generation in corpus cavernosum in high-fat diet/streptozotocin-induced diabetic rats. J Sex Med 9, 18011814, 2012.

Lysiak JJ. The role of tumor necrosis factor-alpha and interleukin-1 in the mammalian testis and their involvement in testicular torsion and autoimmune orchitis. Reprod Biol Endocrinol 2, 9, 2004.

Madrid E, Reyes JG, Hernandez B, Garcia JM, San Martin S, Olivero P, Crespo PV, Parraga M. Effect of normobaric hypoxia on the testis in a murine model. Andrologia 45, 332-338, 2013.

Navarro-Casado L, Juncos-Tobarra MA, Chafer-Rudilla M, Onzono LI, Blazquez-Cabrera JA, Miralles-Garcia JM. Effect of experimental diabetes and STZ on male fertility capacity. Study in rats. J Androl 31, 584-592, 2010.

Noble E, Melling J, Shoemaker K, Tikkanen H, Peltonen J, Stuckey M, Petrella RJ. Innovation to reduce cardiovascular complications of diabetes at the intersection of discovery, prevention and knowledge exchange. Can J Diabetes 37, 282-293, 2013.

Oberbach A, Tonjes A, Kloting N, Fasshauer M, Kratzsch J, Busse MW, Paschke R, Stumvoll M, Bluher M. Effect of a 4 week physical training program on plasma concentrations of inflammatory markers in patients with abnormal glucose tolerance. Eur J Endocrinol 154, 577-585, 2006.

Petersen AM, Pedersen BK. The anti-inflammatory effect of exercise. J Appl Physiol 98, 1154-1162, 2005.

Roy S, Rahaman N, Ahmed F, Metya S, Sannigrahi S. Naringenin attenuates testicular damage, germ cell death and oxidative stress in streptozotocin induced diabetic rats: naringenin prevents diabetic rat testicular damage. J Appl Biomed 11, 195-208, 2013.

Rozwadowska N, Fiszer D, Kurpisz M. Interleukin-1 system in testis - Quantitative analysis: Expression of immunomodulatory genes in male gonad. Adv Exp Med Biol 495, 177-180, 2001.

Safarzade AR, Gharakhanlou R, Hedayati M, Talebi-Garakani E. The Effect of 4 weeks resistance training on serum vaspin, Il-6, CRP and TNF- $\alpha$ concentrations in diabetic rats. Iranian Journal of Endocrinology and Metabolism 14, 68-74, 2012.

Shiraishi K, Naito K. Increased expression of Leydig cell haem oxygenase-1 preserves spermatogenesis in varicocele. Hum Reprod 20, 2608-2613, 2005.

Sisman AR, Kiray M, Camsari UM, Evren M, Ates M, Baykara B, Aksu I, Guvendi G, Uysal N. Potential novel biomarkers for diabetic testicular damage in streptozotocin-induced diabetic rats: nerve growth factor beta and vascular endothelial growth factor. Dis Markers 2014, 108106, 2014. 
Stewart LK, Flynn MG, Campbell WW, Craig BA, Robinson JP, Timmerman KL, McFarlin BK, Coen PM, Talbert E. The influence of exercise training on inflammatory cytokines and C-reactive protein. Med Sci Sports Exerc 39, 1714-1719, 2007.

Talebi-Garakani E, Safarzade A. Resistance training decreases serum inflammatory markers in diabetic rats. Endocrine 43, 564-570, 2013.

Touvra AM, Volaklis KA, Spassis AT, Zois CE, Douda HD, Kotsa K, Tokmakidis SP. Combined strength and aerobic training increases transforming growth factor-betal in patients with type 2 diabetes. Hormones (Athens) 10, 125-130, 2011.

Wachtel TJ, Tetu-Mouradjian LM, Goldman DL, Ellis SE, O’Sullivan PS. Hyperosmolarity and acidosis in diabetes mellitus: a three-year experience in Rhode Island. J Gen Intern Med 6, 495-502, 1991.

Yu Z, Ye X, Wang J, Qi Q, Franco OH, Rennie KL, Pan A, Li H, Liu Y, Hu FB, Lin X. Associations of physical activity with inflammatory factors, adipocytokines, and metabolic syndrome in middle-aged and older chinese people. Circulation 119, 2969-2977, 2009. 